\title{
Optimizing polypharmacy among elderly hospital patients with chronic diseases - study protocol of the cluster randomized controlled POLITE-RCT trial
}

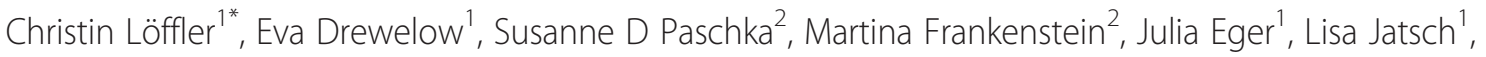 \\ Emil C Reisinger ${ }^{3}$, Johannes F Hallauer ${ }^{4}$, Bernd Drewelow ${ }^{5}$, Karen Heidorn², Helmut Schröder ${ }^{6}$, Anja Wollny ${ }^{1}$, \\ Günther Kundt ${ }^{7}$, Christian Schmidt ${ }^{8}$ and Attila Altiner ${ }^{1}$
}

\begin{abstract}
Background: Treatment of patients with multimorbidity is challenging. A rational reduction of long-term drugs can lead to decreased mortality, less acute hospital treatment, and a reduction of costs. Simplification of drug treatment schemes is also related to higher levels of patient satisfaction and adherence. The POLITE-RCT trial will test the effectiveness of an intervention aiming at reducing the number of prescribed long-term drugs among multimorbid and chronically ill patients. The intervention focuses on the interface between primary and secondary health care and includes a pharmacist-based, patient-centered medication review prior to the patient's discharge from hospital.

Methods: The POLITE-RCT trial is a cluster randomized controlled trial. Two major secondary health care providers of Mecklenburg-Western Pomerania, Germany, take part in the study. Clusters are wards of both medical centers. All wards where patients with chronic diseases and multimorbidity are regularly treated will be included. Patients aged $65+$ years who take five or more prescribed long-term drugs and who are likely to spend at least 5 days in the participating hospitals will be recruited and included consecutively. Cluster-randomization takes place after a six-month baseline data collection period. Patients of the control group receive care as usual. The independent two main primary outcomes are (1) health-related quality of life (EQ-5D) and (2) the difference in the number of prescribed long-term pharmaceutical agents between intervention and control group. The secondary outcomes are appropriateness of prescribed medication (PRISCUS list, Beers Criteria, MAI), patient satisfaction (TSQM), patient empowerment (PEF-FB-9), patient autonomy (IADL), falls, re-hospitalization, and death. The points of measurement are at admission to (T0) and discharge from hospital (T1) as well as 6 and 12 months after discharge from the hospital (T2 and T3). In 42 wards, 1,626 patients will be recruited.
\end{abstract}

Discussion: In case of positive evaluation, the proposed study will provide evidence for a sustainable reduction of polypharmacy by enhancing patient-centeredness and patient autonomy.

Trial registration: Current Controlled Trials ISRCTN42003273

Keywords: Polypharmacy, Drug utilization review, Inappropriate prescribing, Patient-centered care, Secondary care, Primary health care

\footnotetext{
* Correspondence: christin.loeffler@med.uni-rostock.de

'Institute of General Practice, Rostock University Medical Center, Rostock,

Germany

Full list of author information is available at the end of the article
}

\section{Biomed Central}

(c) 2014 Löffler et al.; licensee BioMed Central Ltd. This is an Open Access article distributed under the terms of the Creative Commons Attribution License (http://creativecommons.org/licenses/by/4.0), which permits unrestricted use, distribution, and reproduction in any medium, provided the original work is properly credited. The Creative Commons Public Domain Dedication waiver (http://creativecommons.org/publicdomain/zero/1.0/) applies to the data made available in this article, unless otherwise stated. 


\section{Background}

Along with demographic and epidemiologic changes, polypharmacy becomes a pressing challenge. More and more people suffer from chronic diseases and multimorbidity [1-3] and are treated with an increasing number of drugs. Whereas polypharmacy usually refers to the intake of five or more long-term drugs at the same time [4,5], patients with multiple chronic diseases are often treated with ten or more drugs [6-8]. In Germany, the prevalence of polypharmacy among elderly patients is about $27 \%$ and doubles to $54 \%$ when including over-thecounter medications (OTC) [9].

Treatment of patients with multimorbidity is challenging; medical guidelines tend to focus on a solitary chronic disease. In patients with several chronic diseases conflicting recommendations are likely to occur. Polypharmacy, thus, involves severe risks for patient safety; it is associated with a reduced ability to perform tasks of daily living, with an increased risk for impaired cognitive capacity, and with rising incidence of geriatric syndromes, such as delirium, falls, and urinary incontinence. In addition, patients with polypharmacy witness an increased rate of adverse drug events and drug interactions [10-12]. Among geriatric patients, $10 \%-15 \%$ of all hospital admissions are related to adverse drug events [13]. Adverse drug events increase both morbidity and mortality [12-15]. Previous research shows that a reasonable reduction of long-term drugs can lead to decreased mortality, less acute hospital treatment, and a reduction of costs. Simplification of drug treatment schemes is also related to higher levels of patient satisfaction and adherence [5,14,16-20].

In the past, different tools have been developed to assess and optimize medication in chronically ill patients. In 1991, Beers et al. presented a first catalogue of criteria to detect inappropriate substances among older people-the Beers Criteria for Potentially Inappropriate Medication Use in Older Adults [20,21]. Due to different "markets" and prescribing behavior, countries such as Canada, France, and Germany created their own lists of potentially inappropriate medication (PIM). In 2010, the first German PIM list was published; the PRISCUS list is based on international literature and specific characteristics of Germany. It is systematically consented by experts in the field $[22,23]$.

Furthermore, the usage of OTCs is rising steadily. Very often, though, patients do not perceive OTCs as medication. Although nearly $30 \%$ of German adults periodically make use of herbal preparations-primarily as dietary supplements - they rarely report the usage to their doctors $[24,25]$. Among patients with multimorbidity, who are using a high number of drugs, these dietary supplements can cause severe drug interactions such as bleeding [26] or reduced plasma drug levels [27].
Interventions relying on a concept where pharmacists provide information to clinicians have shown effects on reducing inappropriate prescriptions [12]. Standardized prescription-feedback [28] and educational outreach visits also showed to have some effect towards the reduction of inappropriate multiple medication [12,16,17]. Studies have been conducted in different settings, however, focusing mainly on nursing homes or secondary care. Despite promising results $[11,14,29,30]$, there is still a lack of robust evidence on the sustainability of the effects of medication reviews [31]. Whereas some trials lacked a control group [9,12], others failed to reduce polypharmacy in the long run $[5,32,33]$. As far as the latter are concerned, patients' and primary care physicians' preferences to switch back to the previous medication scheme have been identified as a major problem [34-37]. In sum, there is evidence for the efficacy of well-planned and performed interventions to reduce polypharmacy. However, evidence for effectiveness and efficiency is still lacking, especially as far as effects on patients' quality of life are concerned [38].

\section{Objectives}

The POLITE-RCT trial will test the effectiveness of an intervention aiming at reducing the number of prescribed long-term drugs among multimorbid and chronically ill patients aged $65+$ years. The intervention focuses on the interface between primary and secondary health care and includes a pharmacist-based, patient-centered medication review prior to the patient's discharge from hospital. This approach is innovative and particularly promising, as hospitalization of older, multimorbid and chronically ill patients is often related to an increase in the number of prescribed long-term drugs $[39,40]$. It will be the first trial to systematically assess the effectiveness of the described intervention which is based on both evidence and patient preferences. The POLITE-RCT trial is built on previous research; the POLITE pilot study proved that the intervention is feasible. Reactions of patients, pharmacists, ward physicians, and general practitioners (GPs) were positive. On average, the number of prescribed long-term pharmaceutical agents was reduced by one per patient $[8,41]$.

\section{Methods}

Trial design

The POLITE-RCT trial is a cluster randomized controlled trial. Two major secondary health care providers of Mecklenburg-Western Pomerania, Germany, will take part in the study. Together, both centers with a total of four hospitals treat about 80,000 patients a year in urban and rural settings. The study will, thus, be conducted in a setting that represents the real health service situation. 


\section{Clusters}

Clusters are wards of both medical centers including medical personnel and patients cared for during the observational periods. A ward is defined as an entity with stable medical personnel. In case of responsibility of senior physicians for two or more wards, these wards will be randomized together.

\section{Inclusion criteria}

All wards of the participating centers where elderly patients with chronic diseases and multimorbidity are regularly treated will be included. These are, e.g., units of internal medicine, geriatrics, abdominal and vascular surgery, orthopedic surgery, and neurology.

\section{Exclusion criteria}

Wards currently participating in other trials or projects aiming at optimizing drug therapy will be excluded.

\section{Participants}

\section{Inclusion criteria}

Patients aged 65+ years who take five or more prescribed long-term drugs that are systemically acting (topic administration excluded) and who are likely to spend at least 5 days in the participating hospitals will be recruited and included consecutively.

\section{Exclusion criteria}

Patients who are not able to take their medication by themselves, who are not able to give legal informed consent (e.g., due to dementia), patients with severe language difficulties, and those who suffer from deafness as well as patients taking part in another clinical trial will be excluded. Further, patients with the following diseases that usually make polypharmacotherapy unavoidable are excluded: active malignoma, acquired immunodeficiencies (HIV), and hemodialysis. Also, post-transplant patients as well as patients having a remaining life expectancy of less than 12 months will be excluded.

\section{Recruitment}

Each week, up to 30 eligible patients will be recruited per hospital consecutively at admission. Pharmacists will inform about the study and will seek written informed consent. Recruitment will be stopped as soon as the necessary number of patients per week is reached.

\section{Randomization}

Cluster randomization takes place after a 6-month baseline data collection period. During this period, no intervention will be performed. This allows collecting information about potential confounders and cluster imbalances. Based on that, the decision for or against stratified randomization will be made. Computer-assisted randomization will be performed by a statistician not involved in patient recruitment, data collection, and data management.

\section{Intervention}

During in-patient treatment of patients affected by polypharmacy, a pharmacist specially trained in communication skills performs a narrative-based medication review. Thus, two approaches are combined here: the face-to-face clinical "brown bag" medication review [42] and the patientcentered approach of narrative medicine [43,44]. Apart from detecting potentially inadequate medication, a major aim is to identify patient preferences and to include them-whenever possible-into a hierarchically structured list of evidence-based medication recommendations. Thus, priorities for medication modification can be based on both "objective" pharmaceutical considerations as well as on "subjective" patient preferences. The pilot study showed that this approach motivated patients to actively contribute to the reduction of medication. The narrative-based medication review itself takes approximately 30-45 min. The pharmacist then prepares a list of possible drugs to be stopped. Pharmacists have access to a clinical decision support system [45]. The list will be discussed with the hospital physician in charge and will be submitted for adjustment with the patient's individual GP. The active involvement of the patient's GP aims at bringing transparency into the decision-making and might increase chances for a sustainable optimization of medication by preventing relapse to old medication patterns (as frequently observed in other studies). See Figure 1.

\section{Control group}

Patients attending wards randomized into the control group will not receive a medication review but receive care as usual. Medication data will be obtained from patient records. Contamination between control and intervention group will be minimized by careful and strict separation of functional units.

\section{Outcomes}

\section{Primary outcomes}

The independent two main outcomes are (1) health-related quality of life (EQ-5D) [46-48] and (2) the difference in the number of prescribed long-term pharmaceutical agents between intervention and control group at T3. Since in Germany, combination drugs are frequently used, the primary outcome focuses on pharmaceutical agents rather than on number of drugs.

\section{Secondary outcomes}

The secondary outcomes are appropriateness of prescribed medication (PRISCUS list [22], Beers Criteria [49,50], MAI $[51,52]$ ), patient satisfaction (TSQM) [53,54], patient empowerment (PEF-FB-9) [55], patient autonomy (IADL) 


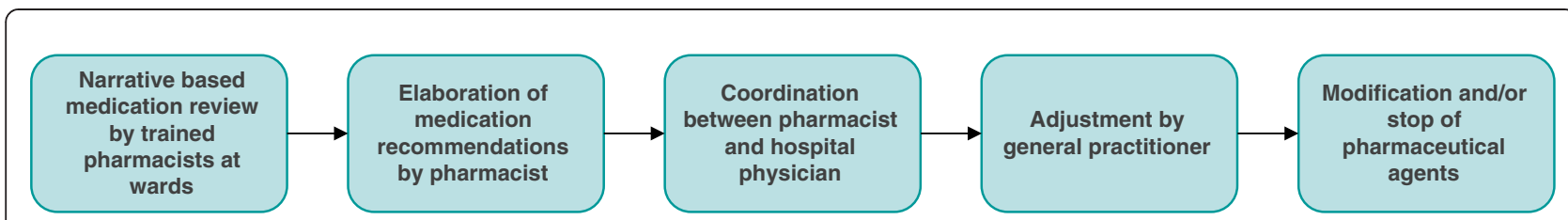

Figure 1 The intervention cascade.

[56], falls (frequency and severity) [57], re-hospitalization, and death. For all patients ensured with the largest public German health insurance provider AOK, costeffectiveness will be analyzed by the Scientific Institute of the AOK (WIdO). In addition, data on socio-demographic characteristics [58] will be collected. See Table 1.

\section{Points of measurement}

Prior to the intervention, baseline data will be collected. During the following intervention period, for each patient of the intervention and control group, primary outcomes will be measured at four points in time: at admission to (T0) and discharge from hospital (T1) as well as 6 and 12 months after discharge from the hospital (T2 and T3).

\section{Blinding}

Patients, pharmacists, physicians, study assistants, and statisticians will not be blinded. Only at T2 and T3, pharmacists will be blinded for data collection.

\section{Sample size}

For the two independent primary outcomes of (1) healthrelated quality of life (EQ-5D) and (2) the difference in prescribed long-term pharmaceutical agents between intervention and control group at 12 months after discharge (T3), the following assumptions are made: for the single summary index of the five dimensions of the EQ-5D descriptive part (using reference value sets for Germany) for the changes from T0 to T3, a mean clinical relevant difference of 0.1 with standard deviation of 0.3 shall be demonstrated between intervention and control. For the difference in prescribed long-term pharmaceutical agents between both groups at 12 months after discharge (T3), a mean difference of 0.5 (number of agents) in reduction of agents with an expected standard deviation of about 1.5 has to be proven. If an EQ-5D difference of 0.1 with standard deviation of 0.3 (or a mean difference of 0.5 in reductions of agents with an expected threefold standard deviation) is to be demonstrated with a power of

Table 1 Overview of instruments and time of measurements

\begin{tabular}{|c|c|c|c|c|c|}
\hline \multirow[t]{2}{*}{ Outcome } & \multirow[t]{2}{*}{ Instrument } & \multicolumn{4}{|c|}{ Time of measurement } \\
\hline & & TO & T1 & $\mathrm{T} 2$ & T3 \\
\hline \multicolumn{6}{|l|}{ Primary outcomes } \\
\hline Health-related quality of life & EQ-5D & $x$ & & $x$ & $X$ \\
\hline $\begin{array}{l}\text { Difference in the number of prescribed } \\
\text { long-term pharmaceutical agents }\end{array}$ & Number of prescribed long-term pharmaceutical agents & $x$ & $x$ & $x$ & X \\
\hline \multicolumn{6}{|l|}{ Secondary outcomes } \\
\hline \multirow[t]{2}{*}{ Appropriateness of prescribed medication } & PRISCUS list, Beers Criteria & $x$ & $x$ & $x$ & $X$ \\
\hline & Medication appropriateness index (MAI) & $x$ & $x$ & $x$ & $X$ \\
\hline Patient satisfaction & TSQM & $x$ & & $x$ & $X$ \\
\hline Patient empowerment & 9-item shared decision-making questionnaire (PEF-FB-9) & $x$ & & $x$ & $X$ \\
\hline Patient autonomy & Instrumental activities of daily living scale (IADL) & $x$ & & $x$ & $X$ \\
\hline \multirow[t]{4}{*}{ Falls } & Frequency: number of falls in the previous 6 months & $x$ & $x$ & $x$ & $X$ \\
\hline & For each fall, severity will be assessed: & & & & \\
\hline & $\begin{array}{l}\text { Moderate: bruising, sprains, cuts, abrasions, or reduction in physical function } \\
\text { for at least three days or if participant sought medical help }\end{array}$ & & & & \\
\hline & Severe: fractures, admission to hospital with an injury, or if stitches were required & & & & \\
\hline Re-hospitalization & & & & $x$ & $X$ \\
\hline Death & & & $x$ & $x$ & $X$ \\
\hline Cost-effectiveness & Difference in health care costs between both groups & & & & $X$ \\
\hline \multicolumn{6}{|l|}{ Additional data } \\
\hline Demographic data & Socio-demographic characteristics in epidemiological studies (SDD) & $x$ & & $x$ & X \\
\hline
\end{tabular}


$80 \%$ at a significance level of $5 \%$ two-sided, a sample size of 143 per group will be required in a randomized trial. For the cluster randomized trial, this sample size has to be multiplied by a design factor of 5.4 [59] if an intra-class correlation coefficient (ICC) of 0.1 and a cluster size of 40 patients is assumed, resulting in a sample size of 1,545 evaluable patients in 38 clusters. Assuming a dropout rate of $5 \%$, a total sample size of 1,626 patients in 42 wards has to be recruited initially. The number of patients per cluster was conservatively defined in order to cope with possible variations that could not be taken into account at the start of the trial. Therefore, sample size estimations will be verified by results of the baseline data analysis. If necessary, adjustments of sample size estimations will be realized. See Figure 2.

\section{Data collection, quality, and monitoring}

The personnel of the participating wards will not be involved in data collection. Instead, data collection will be performed by trained pharmacists and study assistants. Pharmacists will also perform telephone data collection at T2 and T3 and will not receive information about group affiliation of patients. To reduce selection bias, a standardized and scrupulously followed recruitment procedure will be employed, supervised by research assistants and monitored by the Clinical Trial Center North at the University Hospital Hamburg-Eppendorf $(\mathrm{CTCN})$. Monitoring will be conducted according to the standard operation procedures of the Clinical Trial Center North and in compliance with the E6 ICH GCP guideline for good clinical practice. Clinical monitoring will also include review and resolution of missing or inconsistent results and source document checks (i.e., comparison of submitted study results to original reports) to assure the accuracy of the reported data.

\section{Statistical methods}

The unit of inference will be the individual. Then, analyses will be carried out at cluster and at individual level. In a first simple approach, data in each cluster will be collapsed to construct a relevant summary measure (mean with standard deviation). This essentially removes the need to adjust for clustering effects. Of course, for variable-sized clusters, this analysis does neither take into account the intra-cluster correlation nor the cluster sizes and is less efficient than an individual-level analysis. But nevertheless, the relative simplicity of a cluster-level analysis still remains an advantage, albeit with some loss of efficiency and an inability to adjust for individual-level risk factors. In a second step, generalized estimating equations (GEE) models will be applied [60,61]. A generalized linear model takes into account within-group correlation and allows adjustment for the joint effects of cluster-level as well as individual-level factors without the requirement of parametric assumptions.

A model that takes into account the randomized clusters (wards) as random effect, with EQ-5D change or difference in prescribed long-term pharmaceutical agents between intervention and control at T3 as dependent and random group as independent variables, will be fitted to the data. In this model, baseline (T0) values of primary variables and a selection of further baseline characteristics of ward or patient will function as covariates. The intervention effects are quantified by the between-group differences of the corresponding estimates of changes from baseline from the fully adjusted model, which we assume to give the best account of the study results. In the statistical analyses, missing values will not be replaced. Methods for dealing with outliers will be defined in the statistical analysis plan (SAP) or in an addendum to the SAP. Secondary efficacy variables will be analyzed in an explorative way. Similarly, confidence intervals computed will be interpreted as interval estimates for presence or absence of effects in the study data. Intention-to-treat analyses will be performed.

\section{Stopping rules}

Data on death (T1, T2, T3) and hospital re-admissions (T2, T3) of the included patients will be collected. If significant differences in the re-admission rate or number of deaths will be discovered, the safety board will be informed to decide whether to stop or continue the trial.

\section{Ethical approval}

The study was approved by the Ethics Committee at the Rostock University Medical Center in June 2014 with the reference A 2014-0101.

\section{Study registration}

The study has been registered with Current Controlled Trials Ltd. with the reference ISRCTN42003273.

\section{Trial status}

Patient recruitment and baseline data collection started in August 2014.

\section{Discussion}

The POLITE-RCT trial focuses on the pressing challenge of reducing inappropriate medication among elderly patients suffering from chronic diseases. The setting of the study, the German region of Mecklenburg-Western Pomerania offers the particular chance to study the effectiveness of the proposed intervention in an area particularly affected by population aging and an increasing number of people with chronic diseases and multimorbidity [62].

The intervention concept of POLITE-RCT is innovative; as hospitalization of older, multimorbid, and chronically ill 


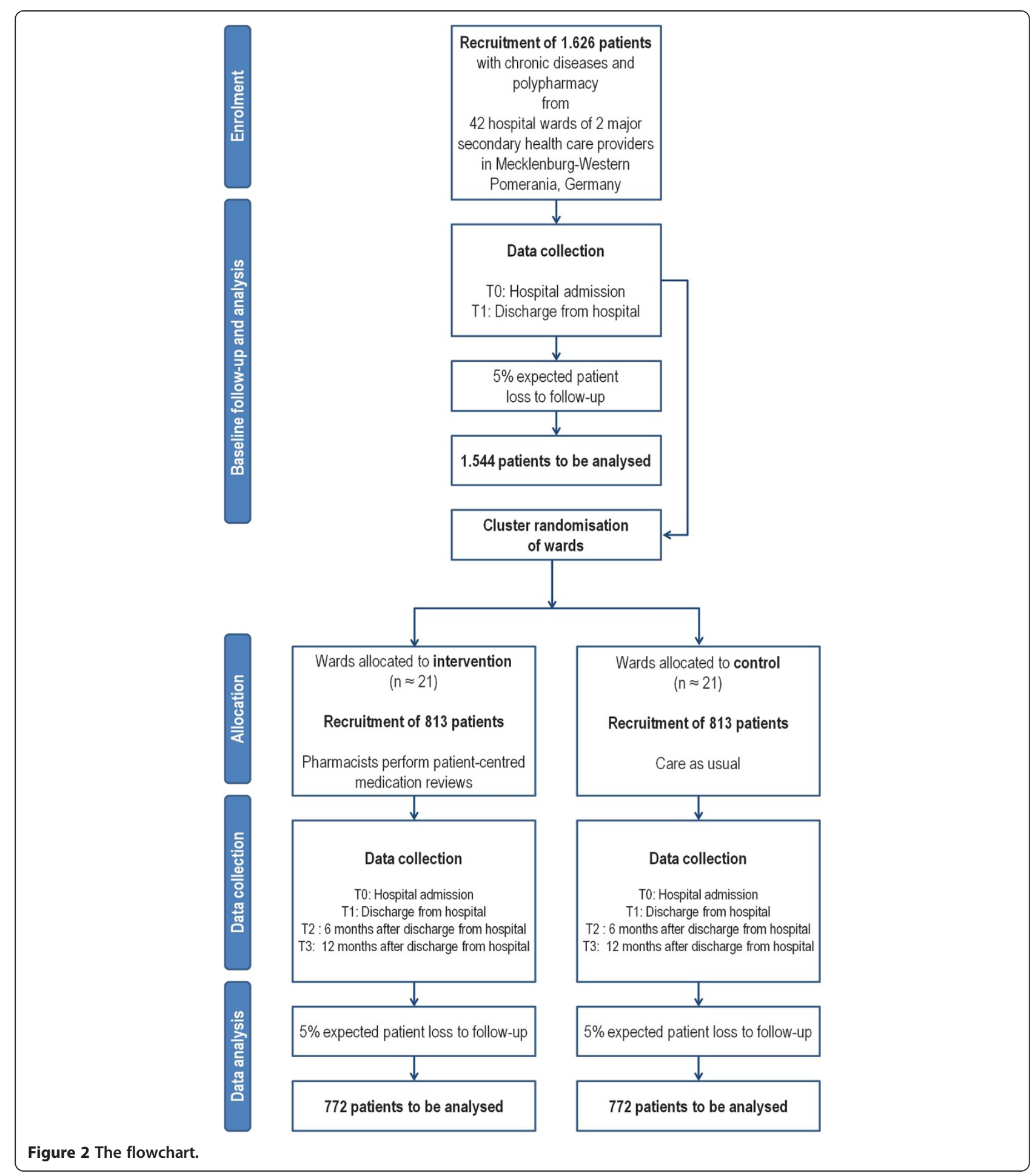

patients is often related to an increase in the number of prescribed long-term drugs [39,40], the focus on the interface between secondary and primary health care is particularly promising. To our knowledge, this is the first trial that systematically assesses the effectiveness of a narrative-based medication review performed by trained pharmacists. Pharmaceutical recommendation will be based on both evidence and patient preferences.

Major methodological strengths of the trial include external monitoring as well as stratified randomization of participating wards after baseline data collection. This way, imbalances between intervention and control group 
will be minimized. Also, based on baseline data, sample size requirements will be adapted.

Potential sources of bias include, e.g., the risk of contamination between intervention and control wards, interviewer bias, and the risk of low inter-rater reliability. To reduce the latter, pharmacists will regularly discuss patient cases and will decide about controversial cases by consensus.

\section{Conclusion}

The POLITE-RCT trial aims at providing robust evidence for the effectiveness of pharmacist-based narrative medication reviews used at the interface between primary and secondary health care. In case of positive evaluation, the proposed study will provide evidence for a sustainable reduction of polypharmacy by enhancing patientcenteredness and patient autonomy. Further, if the trial provides evidence for the cost-effectiveness of the intervention, policy- and other decision-makers might consider implementation into routine care.

\section{Abbreviations}

GEE: generalized estimating equations; GP: general practitioner; ICC: intraclass correlation coefficient; OTC: over-the-counter drugs; PIM: potentially inappropriate medication; SAP: statistical analysis plan.

\section{Competing interests}

The authors declare that they have no competing interests.

\section{Authors' contributions}

$\mathrm{AA}, \mathrm{ECR}, \mathrm{BD}, \mathrm{JH}$, and $\mathrm{CL}$ initiated and designed the study; all authors performed further development. The paper was drafted by $\mathrm{CL}$, and all authors read and approved the final manuscript.

\section{Acknowledgements}

The study is funded by the German Federal Ministry of Education and Research (BMBF, grant number 01GY1332) and was peer reviewed before awarding the funds.

\section{Author details \\ 'Institute of General Practice, Rostock University Medical Center, Rostock, Germany. ${ }^{2}$ Hospital Pharmacy, Rostock University Medical Center, Rostock, Germany. ${ }^{3}$ Department of Internal Medicine II, Rostock University Medical Center, Rostock, Germany. ${ }^{4}$ Dietrich-Bonhoeffer Hospital, Neubrandenburg, Germany. Institute of Pharmacology, Rostock University Medical Center, Rostock, Germany. ${ }^{6}$ AOK Scientific Institute (WIdO), Berlin, Germany. ${ }^{7}$ Institute for Biostatistics and Informatics in Medicine and Ageing Research, Rostock University Medical Center, Rostock, Germany. ${ }^{8}$ Rostock University Medical Center, Rostock, Germany.}

Received: 15 September 2014 Accepted: 23 September 2014 Published online: 06 October 2014

\section{References}

1. Casselli G, Mesle F, Vallin J: Epidemiologic transition theory exceptions. Genus: J Popul Sci 2002, 9:9-51.

2. Harper $\mathrm{K}$, Armelagos $\mathrm{G}$ : The changing disease-shape in the third epidemiological transition. Int J Environ Res Public Health 2010, 7(2):675-697.

3. Schäfer I, von Leitner EC, Schön G, Koller D, Hansen H, Kolonko T, Kaduszkiewicz H, Wegscheider K, Glaeske G, van den Bussche H: Multimorbidity patterns in the elderly: a new approach of disease clustering identifies complex interrelations between chronic conditions. PLoS One 2010, 5(12):e15941.

4. Bregnhøj L, Thirstrup S, Kristensen MB, Bjerrum L, Sonne J: Combined intervention programme reduces inappropriate prescribing in elderly patients exposed to polypharmacy in primary care. Eur I Clin Pharmacol 2009, 65:199-207.

5. Denneboom W, Dautzenberg M, Grol R, De Smet P: Treatment reviews of older people on polypharmacy in primary care: cluster controlled trial comparing two approaches. Br J Gen Prac 2007, 57(542):723-731.

6. Heppner HJ, Christ M, Gosch M, Mühlberg W, Bahrmann P, Bertsch T, Sieber C, Singler K: Polypharmacy in the elderly from the clinical toxicologist perspective. Z Gerontol Geriatr 2012, 45(6):473-478.

7. Boyd CM, Darer J, Boult C, Fried LP, Boult L, Wu AW: Clinical practice guidelines and quality of care for older patients with multiple comorbid diseases: implications for pay for performance. JAMA 2005, 294(6):716-724.

8. Manhart A, Geerdes-Fenge H, Drewelow E, Löffler C, Reisinger E, Heidorn K, Drewelow B, Kundt G, Altiner A: Verminderung von Polypharmazie bei Patienten mit chronischen Erkrankungen (POLITE). In Abschlussbericht für das Ministerium für Arbeit, Gleichstellung und Soziales: Innovative Projekte zur Anpassung der Versorgung an die demografische Entwicklung in MecklenburgVorpommern; 2012

9. Junius-Walker U, Theile G, Hummers-Pradier E: Prevalence and predictors of polypharmacy among older primary care patients in Germany. Fam Pract 2007, 24(1):14-19.

10. Maher RL, Hanlon JT, Hajjar ER: Clinical consequences of polypharmacy in elderly. Expert Opin Drug Saf 2014, 13(1):57-65.

11. Walsh EK, Cussen K: "Take ten minutes": a dedicated ten minute medication review reduces polypharmacy in the elderly. Ir Med J 2010, 103(8):236-238.

12. Maeda K: Systematic review of the effects of improvement of prescription to reduce the number of medications in the elderly with polypharmacy. Yakugaku Zasshi 2009, 129(5):631-645.

13. Schnurrer JU, Frölich JC: Zur Häufigkeit und Vermeidbarkeit von tödlichen unerwünschten Arzneimittelwirkungen. Internist 2003, 44(7):889-895.

14. Garfinkel D, Mangin D: Feasibility study of a systematic approach for discontinuation of multiple medications in older adults: addressing polypharmacy. Arch Intern Med 2010, 170(18):1648-1654

15. Vass M, Hendriksen C: Polypharmacy and other people-the GP perspective. Z Gerontol Geriatr 2005, 38(Suppl 1):114-117.

16. Ostini R, Hegney D, Jackson C, Williamson M, Mackson JM, Gurman K, Hall W, Tett SE: Systematic review of interventions to improve prescribing. Ann Pharmacother 2009, 43(5):502-513.

17. Grindrod KA, Patel P, Martin JE: What interventions should pharmacists employ to impact health practitioners' prescribing practices? Ann Pharmacother 2006, 40(9):1546-1557.

18. Fick DM, Cooper JW, Wade WE, Waller JL, Maclean JR, Beers MH: Updating the Beers criteria for potentially inappropriate medication use in older adults: results of a US consensus panel of experts. Arch Intern Med 2003, 22:2716-2724.

19. Sönnichsen A: Polypharmakotherapie - mehr Medikamente, weniger Gesundheit? Z Allg Med 2011, 3:108-110.

20. Kaduszkiewicz H, Stolzenbach CO, Reich CA, Schäfer I, van den Bussche H, Streich W, Abholz HH, Steinmann S, Wiese B, Löffler C, Altiner A: Wie lässt sich das Chronic Care Model in die hausärztliche Versorgung umsetzen? Presentation and Poster, Colloquium of the BMBF research network "Health in old age", Berlin 1; 2010.

21. Resnick B, Fick DM: 2012 Beers criteria update: how should practicing nurses use the criteria? Geriatr Nurs 2012, 33(4):253-255.

22. Holt S, Schmiedl S, Thürmann PA: Potentially inappropriate medications in the elderly: the PRISCUS list. Dtsch Arztebl Int 2010, 107(31-32):543-551.

23. Amann U, Schmedt N, Garbe E: Prescribing of potentially inappropriate medications for the elderly: an analysis based on the PRISCUS list. Dtsch Arztebl Int 2012, 109(5):69-75

24. Härtel U, Volger E: Inanspruchnahme und Akzeptanz klassischer Naturheilverfahren und alternativer Heilmethoden in Deutschland Ergebnisse einer repräsentativen Bevölkerungsstudie. Forsch Komplementarmed Klass Naturheilkd 2004, 11(6):327-334.

25. Fulton MM, Allen ER: Polypharmacy in the elderly: a literature review. J Am Acad Nurse Pract 2005, 17(4):123-132.

26. Yuan C-S, Wei G, Dey L, Karrison T, Nahlik L, Maleckar S, Kasza K, Ang-Lee M, Moss J: Brief communication: American ginseng reduces warfarin's effect in healthy patients. Ann Intern Med 2004, 141(1):23-27.

27. Bayer Pharma AG: Fachinformation Xarelto Bayer Vital GmbH. Berlin: 2014.

28. Gallagher P, O'Mahony D: STOPP (Screening Tool of Older Persons' potentially inappropriate prescriptions): application to acutely ill elderly patients and comparison with Beers' criteria. Age Ageing 2008, 37(6):673-679. 
29. Hanlon JT, Weinberger M, Samsa GP, Schmader KE, Uttech KM, Lewis IK, Cowper PA, Landsman PB, Cohen HJ, Feussner JR: A randomized, controlled trial of a clinical pharmacist intervention to improve inappropriate prescribing in elderly outpatients with polypharmacy. Am J Med 1996, 100(4):428-437.

30. Jameson JP, VanNoord GR: Pharmacotherapy consultation on polypharmacy patients in ambulatory care. Ann Pharmacother 2001, 35(7-8):835-840.

31. Blenkinsopp A, Bond C, Raynor D: Medication reviews. Br J Clin Pharmacol 2012, 74(4):573-580

32. Meyer TJ, van Kooten D, Marsh S, Prochazka AV: Reduction of polypharmacy by feedback to clinicians. J Gen Intern Med 1991, 6(2):133-136.

33. Williams ME, Pulliam CC, Hunter R, Johnson TM, Owens JE, Kincaid J, Porter $C$, Koch $\mathrm{G}$ : The short-term effect of interdisciplinary medication review on function and cost in ambulatory elderly people. J Am Geriatr Soc 2004, 52(1):93-98.

34. Lampela P, Hartikainen S, Lavikainen P, Sulkava R, Huupponen R: Effects of medication assessment as part of a comprehensive geriatric assessment on drug use over a 1-year period: a population-based intervention study. Drugs Aging 2010, 27(6):507-521.

35. Pitkala $\mathrm{KH}$, Strandberg TE, Tilvis RS: Is it possible to reduce polypharmacy in the elderly? A randomised controlled trial. Drugs Aging 2001, 18(2):143-149.

36. Kroenke K, Pintholt EM: Reducing polypharmacy in the elderly. A controlled trial of physician feedback. J Am Geriatr Soc 1990, 38(1):31-36.

37. Anthierens S, Tansens A, Petrovic M, Christiaens T: Qualitative insights into general practitioners views on polypharmacy. BMC Fam Pract 2010, 11:65.

38. Patterson SM, Hughes C, Kerse N, Cardwell CR, Bradley MC: Interventions to improve the appropriate use of polypharmacy for older people. Cochrane Database Syst Rev 2012, 5:CD008165.

39. Tamblyn R: Medication use in seniors: challenges and solutions. Therapie 1996, 51:269-282

40. Borne R, Cumbler E, Glasheen JJ: Reducing polypharmacy: is hospitalization the right time? Arch Intern Med 2011, 171(9):869.

41. Drewelow E, Manhart A, Geerdes-Fenge H, Heidorn K, Drewelow B, Altiner A, Reisinger E: Pilotstudie zur Optimierung der Schnittstelle aus der sekundären in die primäre Krankenversorgung zur Reduktion von Polypharmazie (POLITE). Z Allg Med 2012; 88 (ZFA Hauptprogramm + Abstractband 2012); Posterbeitrag des 46. DEGAM Kongresses: Rostock; 2012.

42. Clyne W, Blenkinsopp A, Seal R: A Guide to Medication Review. Liverpool: National Prescribing Centre; 2008.

43. Greenhalgh T, Hurwitz B: Narrative based medicine: why study narrative? BMJ 1999, 318(7175):48-50.

44. Greenhalgh T: Narrative based medicine: narrative based medicine in an evidence based world. BMJ 1999, 318(7179):323-325.

45. Seidling HM, Schmitt SP, Bruckner T, Kaltschmidt J, Pruszydlo MG, Senger C, Bertsche T, Walter-Sack I, Haefeli WE: Patient-specific electronic decision support reduces prescription of excessive doses. Qual Saf Health Care 2010, 19(5):1-7.

46. Moock J: Präferenzbasierte Lebensqualitätsmessung: Der EQ-5D Fragebogen. Phys Med Rehab Kuror 2008, 18:245-249.

47. Szende A, Oppe M, Devlin N: Hrsg. EQ-5D Value Sets: Inventory, Comparative Review and User Guide. Dordrecht: Springer; 2007.

48. Greiner W, Claes C, Busschbach JJV, von der Schulenburg JM: Validating the EQ-5D with time trade off for the German population. Eur J Health Econ 2005, 6(2):124-130

49. Beers MH, Ouslander JG, Rollingher I, Reuben DB, Brooks J, Beck JC: Explicit criteria for determining inappropriate medication use in nursing home residents. UCLA Division of Geriatric Medicine Arch Intern Med 1991, 151(9):1825-1832.

50. Schwalbe O, Freiberg I, Kloft C: Die Beers-Liste. Ein Instrument zur Optimierung der Arzneimitteltherapie geriatrischer Patienten. Med Monatsschr Pharm 2007, 30:244-248.

51. Hanlon JT, Schmader KE, Samsa GP, Weinberger M, Uttech KM, Lewis IK, Cohen HJ, Feussner JR: A method for assessing drug therapy appropriateness. J Clin Epidemiol 1992, 45(10):1045-1051.

52. Samsa GP, Hanlon JT, Schmader KE, Weinberger M, Clipp EC, Uttech KM, Lewis IK, Landsman PB, Cohen $\mathrm{HJ}$ : A summated score for the medication appropriateness index: development and assessment of clinimetric properties including content validity. J Clin Epidemiol 1994, 47(8):891-896.

53. Atkinson MJ, Sinha A, Hass SL, Colman SS, Kumar RN, Brod M, Rowland CR: Validation of a general measure of treatment satisfaction, the Treatment
Satisfaction Questionnaire for Medication (TSQM), using a national panel study of chronic disease. Health Qual Life Outcomes 2004, 2:12.

54. Atkinson MJ, Kumar R, Cappelleri JC, Hass SL: Hierarchical construct validity of the treatment satisfaction questionnaire for medication (TSQM version II) among outpatient pharmacy consumers. Value Health 2005, 8(Suppl 1):S9-S24.

55. Kriston L, Scholl I, Hölzel L, Simon D, Loh A, Härter M: The 9-item Shared Decision Making Questionnaire (SDM-Q-9). Development and psychometric properties in a primary care sample. Patient Educ Couns 2010, 80(1):94-99.

56. Lawton MP, Brody EM: Assessment of older people: self-maintaining and instrumental activities of daily living. Gerontologist 1969, 9(3):179-186.

57. Robertson MC, Devlin N, Gardner MM, Campbell AJ: Effectiveness and economic evaluation of a nurse delivered home exercise programme to prevent falls 1: randomised controlled trial. BMJ 2001, 322:697-701.

58. Jöckel KH, Babitsch B, Bellach BM, Bloomfield K, Hoffmeyer-Zlotnik J, Winkler J, Wolf C: Empfehlungen der Arbeitsgruppe "Epidemiologische Methoden" in der Deutschen Arbeitsgemeinschaft Epidemiologie der GMDS und der DGSMP zur Messung und Quantifizierung soziodemographischer Merkmale in epidemiologischen Studien. In Hrsg. Edited by Ahrens W. München: Messung soziodemographischer Merkmale in der Epidemiologie; 1998

59. Altiner A, Brockmann S, Sielk M, Wilm S, Wegscheider K, Abholz HH: Reducing antibiotic prescriptions for acute cough by motivating GPs to change their attitudes to communication and empowering patients: a cluster-randomized intervention study. J Antimicrob Chemother 2007 60(3):638-644

60. Campbell MK, Mollison J, Steen N, Grimshaw JM, Eccles M: Analysis of cluster randomized trials in primary care: a practical approach. Fam Pract 2000, 17(2):192-196

61. Campbell MJ, Donner A, Klar N: Developments in cluster randomized trials and Statistics in Medicine. Stat Med 2007, 26(1):2-19.

62. Muth E, Scholz R, Kruse A, Doblehammer G: Der demografische Wandel in Mecklenburg-Vorpommern - Veränderung der Altersstruktur, demografische Alterung und Schrumpfung von 1982 bis 2007. StatA MV: Statistische Hefte; 2010:2.

doi:10.1186/s13012-014-0151-7

Cite this article as: Löffler et al:: Optimizing polypharmacy among elderly hospital patients with chronic diseases-study protocol of the cluster randomized controlled POLITE-RCT trial. Implementation Science 2014 9:151.

\section{Submit your next manuscript to BioMed Central and take full advantage of:}

- Convenient online submission

- Thorough peer review

- No space constraints or color figure charges

- Immediate publication on acceptance

- Inclusion in PubMed, CAS, Scopus and Google Scholar

- Research which is freely available for redistribution 